\title{
Short versus long duration of dual antiplatelet therapy following drug-eluting stents: a meta-analysis of randomised trials
}

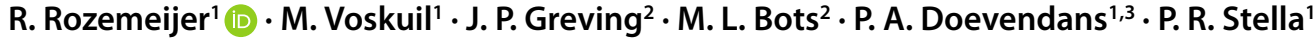 \\ Published online: 14 March 2018 \\ (c) The Author(s) 2018. This article is an open access publication.
}

\begin{abstract}
Background Dual antiplatelet therapy (DAPT) remains the cornerstone therapy in the prevention of ischaemic events following drug-eluting stent (DES) implantation. Mandatory duration of DAPT after DES however, is a matter of debate. We aimed to evaluate safety and efficacy of short-term (up to 6 months) versus long-term (12 months) DAPT after DES implantation.

Methods We searched PubMed, EMBASE, Cochrane databases, and international meetings for randomised clinical trials (RCTs) comparing short with long DAPT. We performed a systematic review and meta-analysis of major trials with primary outcomes: all-cause death, myocardial infarction, definite or probable stent thrombosis, stroke, and major bleeding event. Results Nine RCTs with a total number of 19,099 patients were pooled in the present meta-analysis. When compared with long DAPT, short DAPT was associated with a significant reduction in major bleeding events $(0.62 \%$ vs. $1.10 \%$, risk ratio $(\mathrm{RR}) 0.58,95 \%$ confidence interval $(\mathrm{CI}) 0.39$ to $0.86, p<0.007, \mathrm{I}^{2}=21 \%$ ), whereas all-cause death $(1.65 \%$ vs. $1.84 \%$, RR $0.90,95 \%$ CI 0.73 to $1.11, p=0.34, \mathrm{I} 2=0 \%)$, myocardial infarction $(1.91 \%$ vs. $1.68 \%$, RR $1.14,95 \%$ CI 0.92 to $1.40, p=0.23, \mathrm{I} 2=0 \%)$, definite or probable stent thrombosis $(0.62 \%$ vs. $0.47 \%, \mathrm{RR} 1.25,95 \% \mathrm{CI} 0.84$ to $1.86, p=0.27$, $\mathrm{I} 2=0 \%)$, and stroke $(0.60 \%$ vs. $0.67 \%$, RR $0.91,95 \%$ CI 0.63 to $1.31, p=0.61, \mathrm{I} 2=0 \%)$ were similar.

Conclusions Short DAPT following DES implantation results in a significant reduction of major bleeding events with no apparent increase in all-cause death, myocardial infarction, stent thrombosis, or stroke. Future dedicated trials should investigate the optimal strategies for patient-tailored DAPT in various subgroups.
\end{abstract}

Keywords Coronary artery disease $\cdot$ Drug-eluting stent $\cdot$ Stent thrombosis $\cdot$ Major bleeding events

\section{Introduction}

Dual antiplatelet therapy (DAPT) with aspirin and a P2Y12 inhibitor remains the cornerstone treatment in the prevention of recurrent ischaemic events following drug-eluting stents (DES) implantation. Current guidelines [1, 2] recommend a standard duration of 6 months following newgeneration DES for stable coronary artery disease. A shorter

Electronic supplementary material The online version of this article (https://doi.org/10.1007/s12471-018-1104-6) contains supplementary material, which is available to authorized users.

P. R. Stella

p.stella@umcutrecht.nl

1 Department of Cardiology, University Medical Centre Utrecht, Utrecht, The Netherlands

2 Julius Centrum, Department of Epidemiology, University Medical Centre Utrecht, Utrecht, The Netherlands

3 Netherlands Heart Institute, Utrecht, The Netherlands duration of DAPT may be considered in patients with a high bleeding risk, and a longer duration may be considered for patients with a high ischaemic risk. New-generation DES represent devices with an improved safety profile, and are associated with lower rates of early or late stent thrombosis [3]. This raises the question what the optimal period of DAPT would be following implantation of new-generation DES.

Importantly, several randomised clinical trials have investigated optimal duration of DAPT following DES implantation. However, none of these studies were adequately powered, and some recent trials suffer from event rates that are lower than expected. Hence, we aimed to systematically review current evidence by a meta-analysis of the available randomised controlled trials (RCTs) that compared clinical outcome of short DAPT ( $\leq 6$ months) with long ( $\geq 12$ months) DAPT following DES implantation. 


\section{Methods}

\section{Search strategy and trial selection}

This study was conducted according to the Preferred Reporting Items for Systematic Reviews and Meta-Analyses (PRISMA) statement [4]. We searched PubMed, EMBASE, Cochrane, international websites and meetings for RCTs that compared short (up to 6 months) with long (12 months) DAPT after DES implantation. Our systematic search on the topic of DAPT following PCI which was not limited by language, date or publication status restrictions. Detailed information regarding the full search strategy are shown in supplementary appendix 1.1, together with the PRISMA flow-chart in supplementary appendix 1.2.

\section{Quality assessment and risk of bias}

Two individual investigators (RR and MV) independently carried out the systematic review of evidence and identified studies to be included for analysis. Three authors (RR, $\mathrm{MV}$, and PS) reassessed eligibility of trials and evaluated the trials' quality and risk of bias using the Cochrane collaboration's tool for assessing risk of bias [5], as shown in supplementary appendix 1.3 .

\section{Clinical outcomes}

Main outcomes were all-cause death, myocardial infarction, stroke, and definite or probable stent thrombosis defined by the Academic Research Consortium (ARC) [6]. Major bleeding events were defined by trial definitions. We defined endpoints according to the ARC and adjudicated by an independent clinical event committee for each of the individual studies. Primary and secondary endpoints together with definitions of composite endpoints for each trial are shown in the supplementary appendix 1.4. Four of the included trials (EXCELLENT, RESET, ITALIC, IVUS-XPL) reported bleeding events using the TIMI criteria [7], two (SECURITY, I-LOVE-IT 2) reported bleeding events using the Bleeding ARC (BARC) criteria [8], two reported both TIMI and BARC criteria (PRODIGY, ISAR-SAFE), and one trial (OPTIMIZE) was based on the GUSTO/REPLACE-2 criteria.

\section{Statistical analysis}

All analyses are reported by intention to treat and based on random treatment allocation. For each outcome we calculated risk ratios (RR) and pooled estimates by the MantelHaenszel method [9]. Heterogeneity was estimated using the $\mathrm{I}^{2}$ statistic [10], with value $<25 \%$ being low, a value of 25 to $50 \%$ being moderate, and a value of $>75 \%$ being high. Taking into consideration the substantial differences between trials, we used random-effect models in our analysis.

Additional analyses were carried out to assess a possible impact of ST-elevation myocardial infarction (STEMI) $(\geq 10 \%)$, acute coronary syndrome (ACS) $(\geq 50 \%)$, first-generation DES implants $(\geq 25 \%)$ or B2/C lesion complexity $(\geq 60 \%)$ on clinical outcomes in short and long DAPT. To predict the true value of the RR given the fact that an additional study is published comparing short with long DAPT, we calculated the prediction interval [11]. All analyses were performed using Review Manager (RevMan) version 5.3, Copenhagen, The Nordic Cochrane Centre, The Cochrane Collaboration, 2014.

\section{Results}

Nine RCTs $(n=19,099)$ are included in the present metaanalysis: EXCELLENT [12], RESET [13], PRODIGY [14], OPTIMIZE [15], SECURITY [16], ISAR-SAFE [17], ITALIC [18], I-LOVE-IT 2 [19], and IVUS-XPL [20] with main characteristics shown in Tab. 1. Individual patient characteristics of trials were evenly distributed with a mean age of 64 years, $30 \%$ of patients had diabetes mellitus, and roughly $43 \%$ of patients presented with stable coronary artery disease, whereas $30 \%$ presented as low-risk ACS, as shown in supplementary appendix 1.5. Detailed procedural characteristics were also comparable with $>90 \%$ of the device implants being new-generation as shown in supplementary appendix 1.6. In our analysis short DAPT ranged from 3 to 6 months with a mean duration of 5.1 months, whereas long DAPT ranged from 12 to 24 months with a mean duration of 14.6 months.

Main outcomes of the individual trials are shown in Tab. 2. Two studies (RESET, OPTIMIZE) compared 3 with 12 months of DAPT, five studies (EXCELLENT, SECURITY, ISAR-SAFE, I-LOVE-IT 2, and IVUS-XPL) compared 6 with 12 months of DAPT, and two studies (PRODIGY, ITALIC) compared 6 with 24 months of DAPT. Potential risk of bias was considered to be generally low, albeit most of the trials were open-label (except for ISAR-SAFE), and three trials (SECURITY, ISAR-SAFE, and ITALIC) were prematurely terminated due to recruitment problems. A total of 19,099 patients were randomised and 9526 were assigned to a short regimen of DAPT (up to 6 months), and 9573 patients to long DAPT (at least 12 months). 


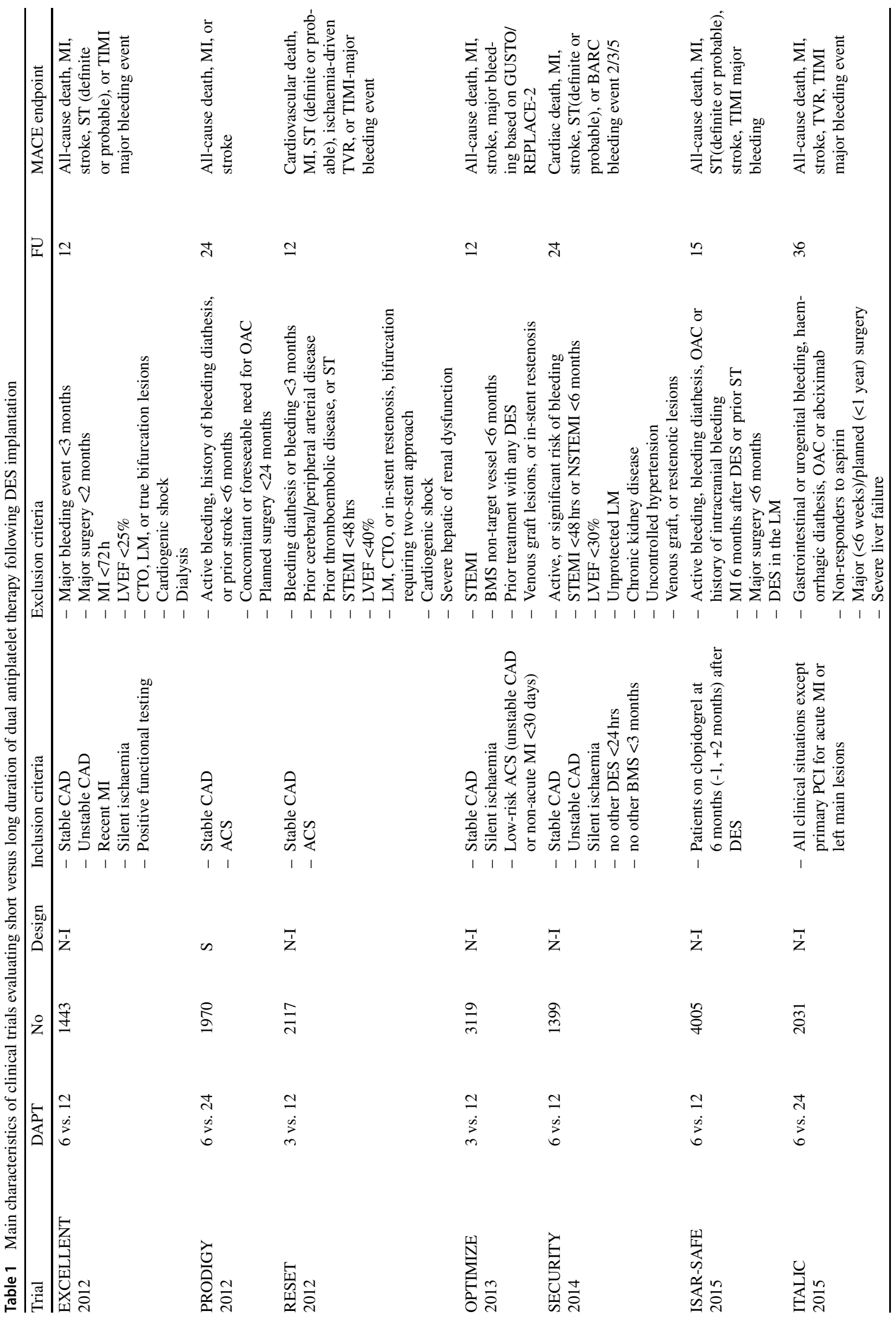




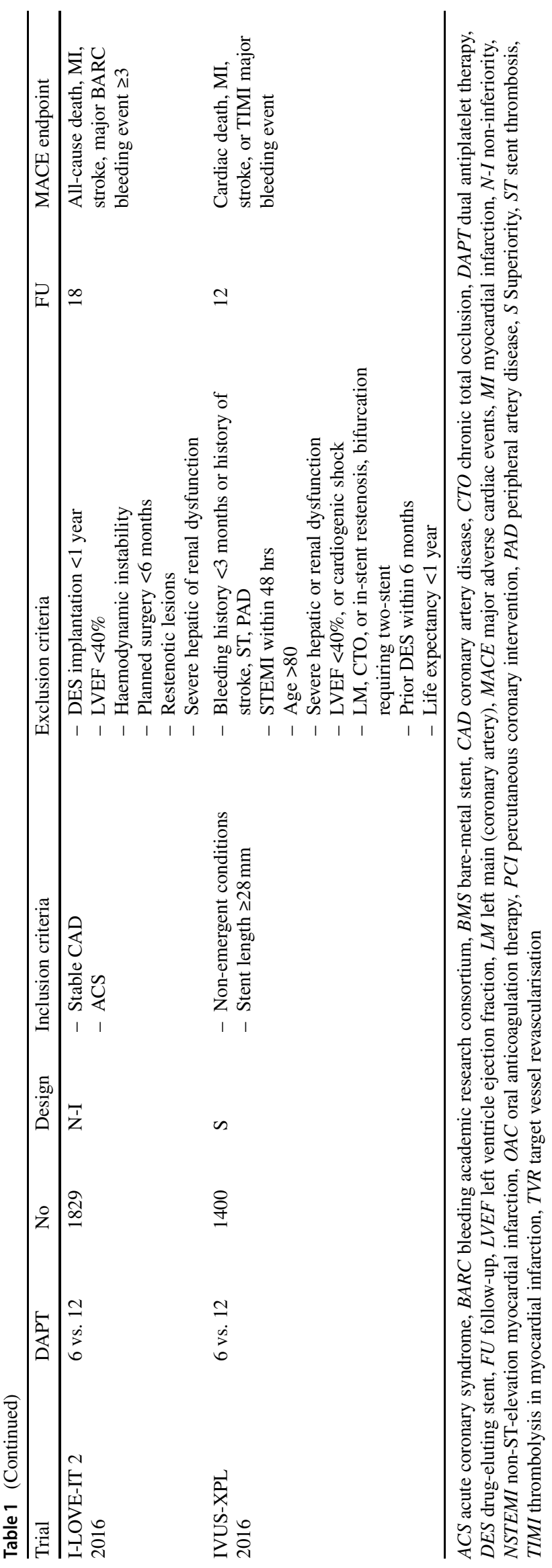

\section{Primary analysis of short versus long DAPT after DES implantation}

The primary outcome for each individual major clinical trial comparing short versus long DAPT are summarised in Fig. 1. This figure shows that short DAPT in patients with low ischaemic risk leads to a significant reduction in major bleeding events, whereas all-cause mortality, myocardial infarction, stent thrombosis, and stroke were similar.

\section{All-cause mortality}

Death rate due to all-causes in patients who underwent PCI with DES implantation was not statistically different for a short duration of DAPT when compared with longer duration of DAPT (Fig. 1a).

\section{Myocardial infarction}

Myocardial infarction was numerically higher in short DAPT when compared with long DAPT, without reaching the level of statistical significance (Fig. 1b).

\section{Stent thrombosis}

The overall rate of definite or probable stent thrombosis was $0.56 \%$. Differences among the rate of stent thrombosis in short versus long DAPT did not reach the level of statistical significance (Fig. 1c).

\section{Stroke}

We did not detect any differences in cerebrovascular accidents for short DAPT when compared with long DAPT (Fig. 1d).

\section{Major bleeding events}

The overall rate of major bleeding events was $0.86 \%$. Major bleeding rates were available for all trials included in this meta-analysis, although the event rates reported by four trials were defined based on TIMI criteria, two were based on BARC criteria, and one was based on modified REPLACE2/GUSTO criteria. Short duration of DAPT was associated with a significant reduction in the risk of major bleeding events (event rate $0.62 \%$ vs. $1.10 \%$, RR $0.58,95 \%$ CI 0.39 to $0.86, p<0.007, \mathrm{I}^{2}=21 \%$, see Fig. $1 \mathrm{e}$ ).

\section{Sensitivity analysis}

The results obtained with sensitivity analyses were highly consistent, and did not modify any of our main findings. 
Table 2 Clinical outcomes of clinical trials evaluating short versus long duration of dual antiplatelet therapy following DES implantation

\begin{tabular}{|c|c|c|c|c|c|c|c|}
\hline Trial & $\begin{array}{l}\text { Short vs. long } \\
\text { DAPT }\end{array}$ & $\begin{array}{l}\text { MACE/MACCE } \\
\text { endpoint } \\
\text { short vs. long }\end{array}$ & $p$-value & $\begin{array}{l}\text { Major bleeding } \\
\text { event } \\
\text { short vs. long }\end{array}$ & $p$-value & $\begin{array}{l}\text { Definite or proba- } \\
\text { ble ST } \\
\text { short vs. long }\end{array}$ & $p$-value \\
\hline EXCELLENT & 6 vs. 12 & $\begin{array}{l}8.0 \% \text { vs. } 8.5 \%^{1} \\
\text { HR } 0.94(0.65 \text { to } \\
1.35)\end{array}$ & 0.72 & $\begin{array}{l}0.3 \% \text { vs. } 0.6 \%^{2} \\
\text { HR } 0.50(0.09 \text { to } \\
2.73)\end{array}$ & 0.42 & $\begin{array}{l}0.9 \% \text { vs. } 0.1 \% \\
\text { HR } 6.02(0.72 \text { to } \\
50)\end{array}$ & 0.10 \\
\hline PRODIGY & 6 vs. 24 & $\begin{array}{l}10.0 \% \text { vs } 10.1 \%^{3} \\
\text { HR } 0.98(0.74 \text { to } \\
1.29)\end{array}$ & 0.91 & $\begin{array}{l}1.9 \% \text { vs. } 3.4 \%^{4} \\
\text { HR } 0.56(0.32 \text { to } \\
0.98)\end{array}$ & 0.037 & $\begin{array}{l}1.5 \% \text { vs. } 1.3 \% \\
\text { HR } 1.15(0.55 \text { to } \\
2.44)\end{array}$ & 0.70 \\
\hline RESET & 3 vs. 12 & $\begin{array}{l}4.7 \% \text { vs. } 4.7 \%^{5} \\
\text { RD } 0.0 \%[-2.5 \text { to } \\
2.5]\end{array}$ & 0.84 & $\begin{array}{l}0.2 \% \text { vs. } 0.6 \%{ }^{6} \\
\mathrm{RD}-0.4 \%[-0.9 \text { to } \\
0.1]\end{array}$ & 0.16 & $\begin{array}{l}0.2 \% \text { vs. } 0.3 \% \\
\text { RD }-0.1 \%[-0.5 \\
\text { to } 0.3]\end{array}$ & 0.65 \\
\hline OPTIMIZE & 3 vs. 12 & $\begin{array}{l}6.0 \% \text { vs. } 5.8 \%^{7} \\
\text { HR } 1.03(0.77 \text { to } \\
1.38)\end{array}$ & 0.84 & $\begin{array}{l}0.6 \% \text { vs. } 0.9 \%^{8} \\
\text { HR } 0.71(0.32 \text { to } \\
1.60)\end{array}$ & 0.41 & $\begin{array}{l}0.8 \% \text { vs. } 0.8 \% \\
\text { HR } 1.08(0.49 \text { to } \\
2.36)\end{array}$ & 0.86 \\
\hline SECURITY & 6 vs. 12 & $\begin{array}{l}4.5 \% \text { vs. } 3.7 \% 9 \\
\text { RD } 0.8 \%[-2.4 \text { to } \\
1.7]\end{array}$ & 0.47 & $\begin{array}{l}0.6 \% \text { vs. } 1.1 \%{ }^{10} \\
\text { RD }-0.5 \%[-1.4 \text { to } \\
0.4]\end{array}$ & 0.28 & $\begin{array}{l}0.3 \% \text { vs. } 0.4 \% \\
\mathrm{RD}-0.1 \%[-0.7 \\
\text { to } 0.4]\end{array}$ & 0.69 \\
\hline ISAR-SAFE & 6 vs. 12 & $\begin{array}{l}1.5 \text { vs. } 1.6^{11} \\
\text { HR } 0.91(0.55 \text { to } \\
1.50)\end{array}$ & 0.70 & $\begin{array}{l}1.0 \% \text { vs. } 2.0 \%^{12} \\
\text { HR } 0.50(0.29 \text { to } \\
0.85)\end{array}$ & 0.01 & $\begin{array}{l}0.3 \% \text { vs. } 0.2 \% \\
\text { HR } 1.25(0.33 \text { to } \\
4.65)\end{array}$ & 0.74 \\
\hline ITALIC & 6 vs. 24 & $\begin{array}{l}1.6 \% \text { vs. } 1.5 \%{ }^{13} \\
\text { HR } 1.07(0.51 \text { to } \\
2.22)\end{array}$ & 0.85 & $\begin{array}{l}0.0 \% \text { vs. } 3.0 \%^{14} \\
\text { NA }\end{array}$ & - & $\begin{array}{l}3.0 \% \text { vs. } 0.0 \% \\
\text { N/A }\end{array}$ & - \\
\hline I-LOVE-IT 2 & 6 vs. 12 & $\begin{array}{l}7.2 \% \text { vs. } 6.4 \%^{15} \\
\text { NA }\end{array}$ & 0.53 & $\begin{array}{l}0.7 \% \text { vs } 1.2 \%^{16} \\
\text { NA }\end{array}$ & 0.21 & $\begin{array}{l}1.1 \% \text { vs. } 0.8 \% \\
\text { N/A }\end{array}$ & 0.33 \\
\hline IVUS-XPL & 6 vs. 12 & $\begin{array}{l}2.2 \% \text { vs. } 2.1 \%^{17} \\
\text { HR } 1.07(0.52 \text { to } \\
2.22)\end{array}$ & 0.85 & $\begin{array}{l}0.7 \% \text { vs. } 1.0 \%{ }^{18} \\
\text { HR } 0.71(0.23 \text { to } \\
2.25)\end{array}$ & 0.56 & $\begin{array}{l}0.3 \% \text { vs. } 0.3 \% \\
\text { HR } 1.00(0.14 \text { to } \\
7.11)\end{array}$ & 0.99 \\
\hline
\end{tabular}

${ }^{1}$ MACCE (1-year): any death, MI, stroke, or any revascularisation; ${ }^{2}$ TIMI major bleeding event; ${ }^{3} \mathrm{MACCE}\left(2\right.$-year): any death, MI, stroke; ${ }^{4} \mathrm{BARC}$ $3 / 5$ major bleeding event; ${ }^{5} \mathrm{MACE}$ (1-year): cardiovascular death, MI, ST (def. or prob.), ischaemia-driven TVR, or TIMI bleeding; ${ }^{6}$ TIMI major bleeding event; ${ }^{7}$ MACCE (1-year): any death, MI, stroke, or major bleeding; ${ }^{8}$ REPLACE-GUSTO; ${ }^{9}$ MACCE (1-year): cardiac death, MI, stroke, ST (def. or prob.), or BARC 3/5; ${ }^{10}$ BARC $3 / 5$ major bleeding event; ${ }^{11}$ MACCE (15-months): any death, MI, ST (def. or prob.), stroke, or TIMI major bleeding; ${ }^{12}$ BARC 2/3/5 bleeding event; ${ }^{13} \mathrm{MACCE}$ (1-year): any death, MI, stroke, TVR, or TIMI major bleeding; ${ }^{14} \mathrm{TIMI}$ major bleeding event; ${ }^{15} \mathrm{MACCE}$ (1-year): any death, MI, stroke, major bleeding BARC $\geq 3 ;{ }^{16} \mathrm{BARC} 3 / 4 / 5$ major bleeding event; ${ }^{17} \mathrm{MACCE}$ (1-year): cardiac death, MI, stroke, TIMI major bleeding; ${ }^{18}$ TIMI major bleeding event

$B A R C$ bleeding academic research consortium, DAPT dual antiplatelet therapy, $H R$ hazard ratio, MACE major adverse cardiac events,

$M A C C E$ major adverse cardiac and cerebrovascular events, $M I$ myocardial infarction, $N / A$ not available, $R D$ risk difference, $S T$ stent thrombosis,

$T I M I$ thrombolysis in myocardial infarction, TVR target vessel revascularisation

We carried out additional analyses to investigate the impact of studies with a relatively high number of STEMI $(\geq 10 \%)$, ACS ( $\geq 50 \%)$, first-generation DES ( $\geq 25 \%)$, and complex lesions $(\geq 60 \%)$.

\section{Prediction interval}

Regarding the primary analysis comparing short with long DAPT, the likely values of the true RR were calculated considering that a new study will be published. Most endpoints (all-cause mortality, myocardial infarction, stent thrombosis, and stroke) did not show considerable heterogeneity and therefore the $95 \%$ CI could be interpreted as a prediction interval. Regarding major bleeding events, however, the $95 \%$ prediction interval is considered to range from 0.31 to 1.06 .

\section{Discussion}

In this meta-analysis, which included more than nineteen thousand randomised patients scheduled for PCI with DES implantation, we evaluated clinical outcomes of short versus long DAPT. Several trials have been conducted to evaluate DAPT following stent implantation. However, the optimal duration of DAPT remains controversial, and none of these trials [12-19] were adequately powered.

Our findings demonstrate that (1) short DAPT, when compared with long DAPT, was associated with a reduction of roughly $50 \%$ in major bleeding events, and (2) short DAPT was not associated with an apparent increase of allcause death, myocardial infarction, stent thrombosis, or stroke. Our findings support the use of short DAPT in stable patients, as we believe that prolongation of DAPT regimens will result in a detrimental increase in bleeding 


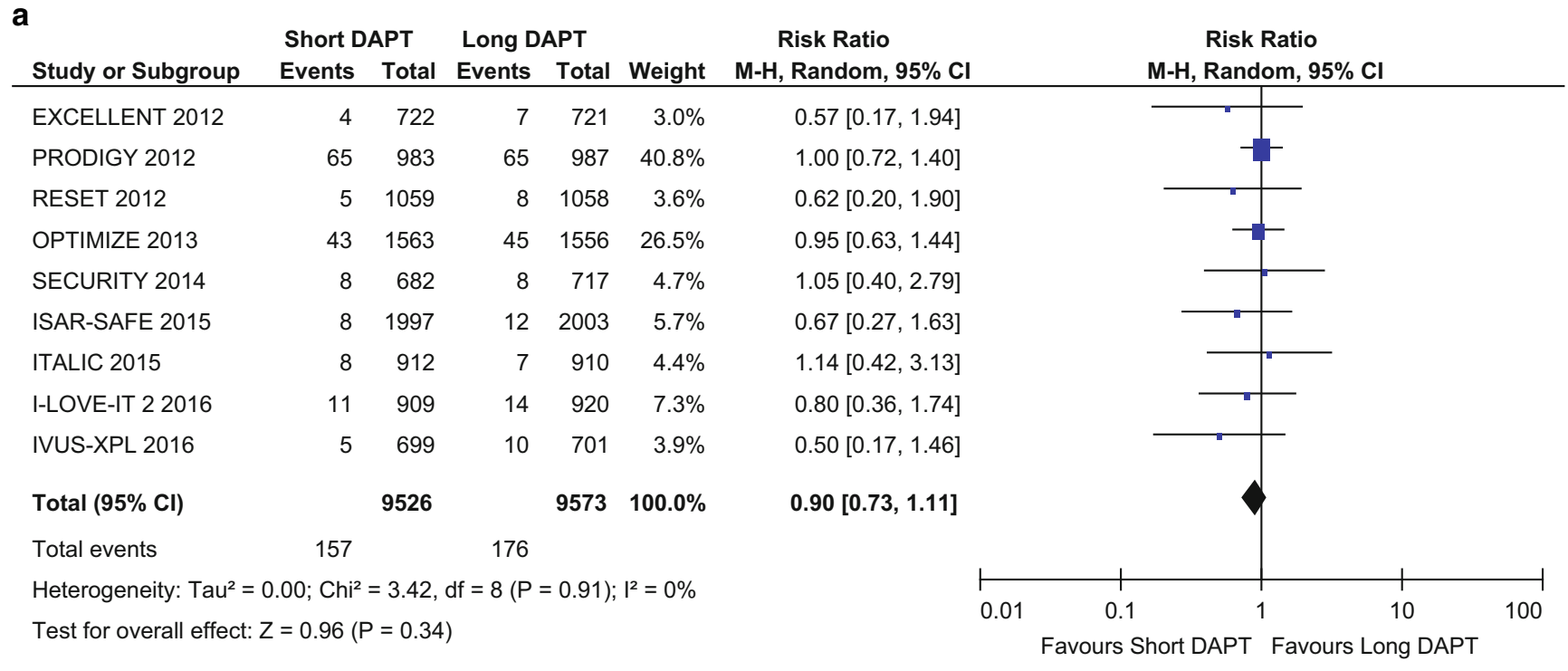

b

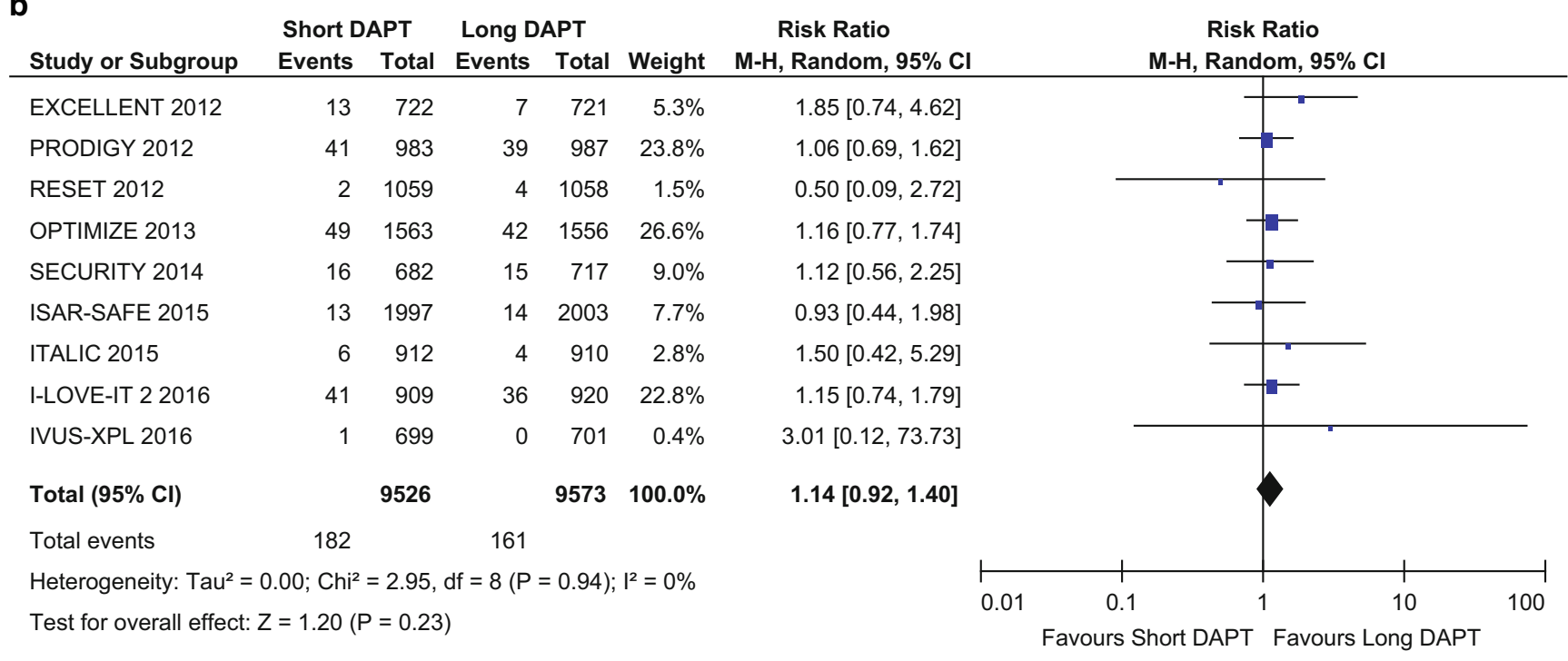

Fig. 1 Forest plots reporting of pooled risk ratios with 95\% confidence intervals of a all-cause mortality; b myocardial infarction; c probable or definite stent thrombosis; d stroke; e BARC $\geq 3$ major bleeding event. Horizontal lines represent the $95 \%$ confidence interval, the square represents the risk ratio of each individual study, the diamond represents the pooled risk ratios and the overall effect. DAPT dual antiplatelet therapy, $C I$ confidence interval, $M-H$ Mantel-Haenszel

events. High-risk patients on the other hand, may benefit from a longer duration of DAPT and are beyond the scope of this analysis as our primary analysis is not powered for this particular subgroup.

Several meta-analyses evaluated short versus long DAPT. The findings of our meta-analysis differ from the previous meta-analyses that were carried out with fewer patients in the short DAPT regimen [21-23] or with higher heterogeneity [21, 24-26]. Consistent with our findings, previous meta-analyses have shown that short DAPT is associated with lower rates of major bleeding events when compared with long DAPT $[22,23]$. We should emphasise that bleeding events due to DAPT are time-independent, meaning that the overall risk of bleeding will continue to rise with longer durations of DAPT. In contrast to previous meta-analyses $[22,27]$, short DAPT did not lead to an increased rate of ischaemic events in our analysis, which may be due to the fact that our analysis contains a considerable number of stable patients and may not be valid for high-risk patients. For instance, a subgroup that may particularly benefit from longer durations of DAPT are stable patients with a history of myocardial infarction, as demonstrated by a recent metaanalysis [28].

Nearly two decades ago, DAPT was shown superior in ACS in terms of efficacy when compared with aspirin alone [29]. A landmark analysis of CURE revealed that the ma- 
C

Short DAPT Long DAPT Risk Ratio

Study or Subgroup Events Total Events Total Weight M-H, Random, 95\% $5.99[0.72,49.64]$

EXCELLENT 2012

$\begin{array}{lllll}6 & 722 & 1 & 721 & 3.5 \%\end{array}$

PRODIGY 2012

RESET 2012

OPTIMIZE 2013

$15 \quad 983$

$13 \quad 987 \quad 28.7 \%$

$1.16[0.55,2.42]$

$2 \quad 1059 \quad 3 \quad 1058 \quad 4.9 \%$

$0.67[0.11,3.98]$

SECURITY 2014

$13 \quad 1563$

$12 \quad 1556 \quad 25.6 \%$

$1.08[0.49,2.36]$

$0.70[0.12,4.18]$

ISAR-SAFE 2015

$2 \quad 682$

$3 \quad 717$

$4.9 \%$

$5 \quad 1997$

42003

$1.25[0.34,4.66]$

ITALIC 2015

3912

$0 \quad 910 \quad 1.8 \%$

I-LOVE-IT 22016

11909

$\begin{array}{lll}7 & 920 & 17.5 \%\end{array}$

IVUS-XPL 2016

2699

$2701 \quad 4.1 \%$

Total $(95 \% \mathrm{Cl})$

9526

$9573 \quad 100.0 \%$

Total events

$59 \quad 45$

Heterogeneity: $\mathrm{Tau}^{2}=0.00 ; \mathrm{Chi}^{2}=4.82, \mathrm{df}=8(\mathrm{P}=0.78) ; \mathrm{I}^{2}=0 \%$

Test for overall effect: $Z=1.11(P=0.27)$

$6.98[0.36,135.03]$

$1.59[0.62,4.08]$

$1.00[0.14,7.10]$

$1.25[0.84,1.86]$

d

Short DAPT Long DAPT

Risk Ratio

M-H, Random, 95\% C

Study or Subgroup Events Total Events Total Weight $\mathrm{M}-\mathrm{H}, \mathrm{Random}, \mathbf{9 5} \% \mathrm{Cl}$

EXCELLENT 2012

PRODIGY 2012

RESET 2012

OPTIMIZE 2013

SECURITY 2014

ISAR-SAFE 2015

ITALIC 2015

I-LOVE-IT 22016

IVUS-XPL 2016

Total $(95 \% \mathrm{Cl})$

9526

3722

$5721 \quad 6.6 \%$

14983

$21 \quad 987$

$29.9 \%$

51059

51563

$6 \quad 682$

$\begin{array}{ll}7 & 1997\end{array}$

$0 \quad 912$

11909

$6 \quad 699$

$6 \quad 1058$

$9.6 \%$

51556

$8.8 \%$

$2717 \quad 5.3 \%$

$5 \quad 2003 \quad 10.2 \%$

Total events

57

$4 \quad 910 \quad 1.6 \%$

$13 \quad 920 \quad 21.1 \%$

$3701 \quad 7.0 \%$

$9573 \quad 100.0 \%$

64

Heterogeneity: $\mathrm{Tau}^{2}=0.00 ; \mathrm{Chi}^{2}=7.33, \mathrm{df}=8(\mathrm{P}=0.50) ; \mathrm{I}^{2}=0 \%$

Test for overall effect: $Z=0.51(P=0.61)$

e

Short DAPT Long DAPT

Events Total Events Total Weight

EXCELLENT 2012
PRODIGY 2012
RESET 2012
OPTIMIZE 2013
SECURITY 2014
ISAR-SAFE 2015
ITALIC 2015
I-LOVE-IT 22016
IVUS-XPL 2016

$\begin{array}{rr}2 & 722 \\ 19 & 983 \\ 2 & 1059 \\ 10 & 1563 \\ 4 & 682 \\ 6 & 1997 \\ 0 & 912 \\ 11 & 909 \\ 5 & 699\end{array}$

Total $(95 \% \mathrm{Cl})$

9526

$\begin{array}{rrr}4 & 721 & 4.9 \% \\ 34 & 987 & 26.2 \% \\ 6 & 1058 & 5.4 \% \\ 14 & 1556 & 16.5 \% \\ 8 & 717 & 9.0 \% \\ 23 & 2003 & 14.2 \% \\ 3 & 910 & 1.7 \% \\ 6 & 920 & 12.2 \% \\ 7 & 701 & 9.7 \% \\ & 9573 & 100.0 \%\end{array}$

Total events

59

105

Heterogeneity: $\mathrm{Tau}^{2}=0.07 ; \mathrm{Chi}^{2}=10.12, \mathrm{df}=8(\mathrm{P}=0.26) ; \mathrm{I}^{2}=21 \%$

Test for overall effect: $Z=2.70(P=0.007)$

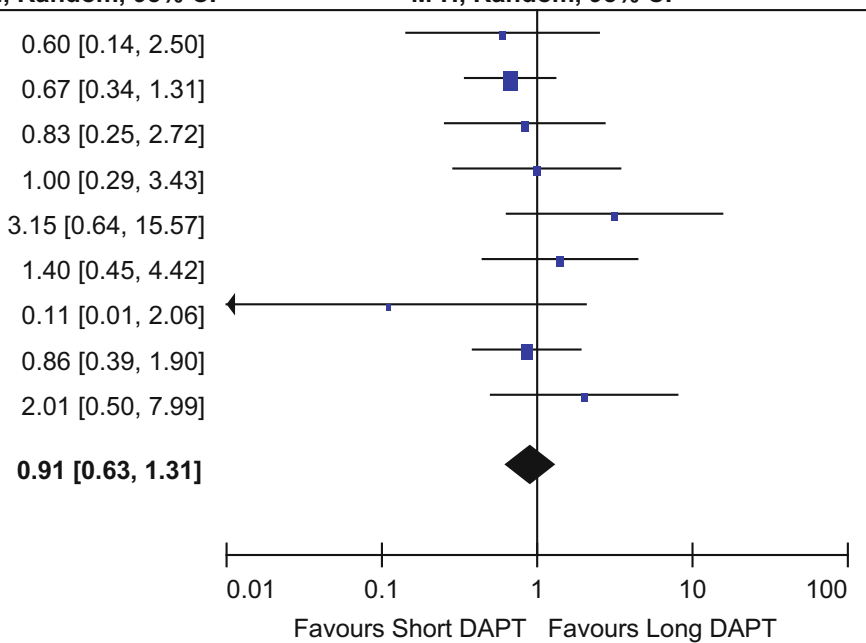

Risk Ratio

M-H, Random, $95 \% \mathrm{Cl}$

Risk Ratio

M-H, Random, $95 \% \mathrm{Cl}$
$0.50[0.09,2.72]$
$0.56[0.32,0.98]$
$0.33[0.07,1.65]$
$0.71[0.32,1.60]$
$0.53[0.16,1.74]$
$0.26[0.11,0.64]$
$0.14[0.01,2.76]$
$1.86[0.69,5.00]$
$0.72[0.23,2.25]$
$0.58[0.39,0.86]$

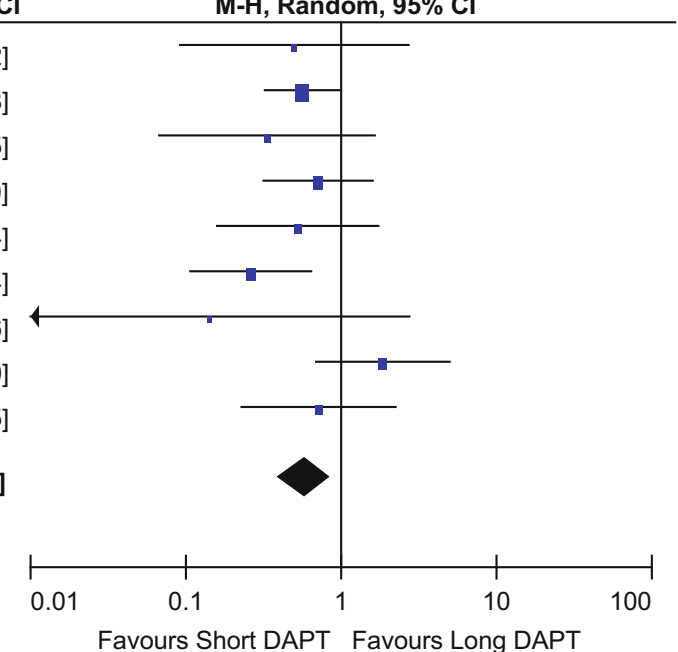

Fig. 1 continued 
jority of ischaemic events are prevented within the first 3 months (20/1,000 patients treated). After this period, this protective effect is substantially attenuated $(2 / 1,000$ patients treated) and the rate of significant bleeding events may become more important than the number of prevented ischaemic events. What is complicating our interpretation, however, is that this pivotal study was conducted in the BMS era and a considerable number of patients with ACS were being treated conservatively. A recent meta-analysis [30] demonstrated that a short duration of DAPT (3 months) in ACS was associated with higher rates of myocardial infarction and stent thrombosis. Some clinicians consider major bleeding events less deleterious when compared with acute ischaemic events. Noteworthy, post-discharge bleeding events are still common and directly associated with increased mortality. In fact, post-discharge major bleeding events should not be underestimated as the effect size is sometimes even greater than that of post-discharge myocardial infarction [31]. Opposing this statement is a substudy of ADAPT-DES [32] that evaluated the impact of stent thrombosis, myocardial infarction that is not stent-related, and clinically relevant bleeding events on mortality, and found that the risk of mortality was increased in both post-PCI ischaemic and bleeding events. Remarkably, early stent thrombosis and very late spontaneous myocardial infarction were associated with the highest risk of mortality, whereas clinically significant bleeding events and myocardial infarction that is not stent-related were associated with a similar but lower risk of mortality.

\section{Limitations}

Some limitations in the present meta-analysis should be acknowledged. First, a meta-analysis of individual patient data would allow us to directly analyse parameters influencing outcomes following short or long DAPT. We believe, however, that we can reliably evaluate the topic of interest with our approach. Second, the reported event rate (death, myocardial infarction and stroke) in some trials was $>10 \%$ (PRODIGY), whereas the event rate (death, myocardial infarction, target vessel revascularisation and bleeding) of others was as low as $1.5 \%$ (ITALIC), and may therefore be indicative for underreporting in some of the studies in this meta-analysis. The accuracy of our results reflects the quality of the included studies. Some variance was introduced by clinical endpoint definitions, especially in bleeding event endpoints. The conservative definitions for major bleeding events that some trials used may have underestimated the rate of major bleeding events as we believe should be evaluated by the BARC criteria. Even though endpoint definitions were not uniform, we suppose this did not modify our overall conclusion. Finally, in most trials clopidogrel was used as a P2Y12 inhibitor. Considering the frequent use of more potent $\mathrm{P} 2 \mathrm{Y} 12$ inhibitors in routine clinical practice, the incidence of major bleeding events in our analysis may be underestimated.

\section{Conclusions}

A short regimen of DAPT after PCI using a DES implantation seems to provide a significant reduction in major bleeding events without compromising ischaemic events in patients with stable coronary artery disease. To drive patient-tailored antiplatelet therapy, the delicate balance of bleeding complications as opposed to the risk of ischaemic events should be investigated in patient-specific subgroups.

Conflict of interest R. Rozemeijer, M. Voskuil, J.P. Greving, M.L. Bots, P.A. Doevendans and P.R. Stella declare that they have no competing interests.

Open Access This article is distributed under the terms of the Creative Commons Attribution 4.0 International License (http:// creativecommons.org/licenses/by/4.0/), which permits unrestricted use, distribution, and reproduction in any medium, provided you give appropriate credit to the original author(s) and the source, provide a link to the Creative Commons license, and indicate if changes were made.

\section{References}

1. Valgimigli M, Bueno H, Byrne RA, et al. 2017 ESC focused update on dual antiplatelet therapy in coronary artery disease developed in collaboration with EACTS: The Task Force for dual antiplatelet therapy in coronary artery disease of the European Society of Cardiology (ESC) and of the European Association for Cardio-Thoracic Surgery (EACTS). Eur Heart J. 2017;39(3):213-60.https://doi.org/ 10.1093/eurheartj/ehx419.

2. Evidence Review Committee M, Bittl JA, Baber U, Bradley SM, Wijeysundera DN. Duration of dual antiplatelet therapy: a systematic review for the 2016 ACC/AHA guideline focused update on duration of dual antiplatelet therapy in patients with coronary artery disease: a report of the American college of cardiology/American heart association task force on clinical practice guidelines. Circulation. 2016;134:e156-e78.

3. Palmerini T, Biondi-Zoccai G, Della Riva D, et al. Stent thrombosis with drug-eluting and bare-metal stents: evidence from a comprehensive network meta-analysis. Lancet. 2012;379:1393-402.

4. Liberati A, Altman DG, Tetzlaff J, et al. The PRISMA statement for reporting systematic reviews and meta-analyses of studies that evaluate healthcare interventions: explanation and elaboration. BMJ. 2009;339:b2700.

5. Higgins JP, Altman DG, Gotzsche PC, et al. The Cochrane Collaboration's tool for assessing risk of bias in randomised trials. BMJ. 2011;343:d5928.

6. Cutlip DE, Windecker S, Mehran R, et al. Clinical end points in coronary stent trials: a case for standardized definitions. Circulation. 2007;115:2344-51.

7. Rao AK, Pratt C, Berke A, et al. Thrombolysis in Myocardial Infarction (TIMI) Trial-phase I: hemorrhagic manifestations and changes in plasma fibrinogen and the fibrinolytic system in pa- 
tients treated with recombinant tissue plasminogen activator and streptokinase. J Am Coll Cardiol. 1988;11:1-11.

8. Mehran R, Rao SV, Bhatt DL, et al. Standardized bleeding definitions for cardiovascular clinical trials: a consensus report from the Bleeding Academic Research Consortium. Circulation. 2011;123:2736-47.

9. Mantel N, Haenszel W. Statistical aspects of the analysis of data from retrospective studies of disease. J Natl Cancer Inst. 1959;22:719-48.

10. Higgins JP, Thompson SG, Deeks JJ, Altman DG. Measuring inconsistency in meta-analyses. BMJ. 2003;327:557-60.

11. Higgins JP, Thompson SG, Spiegelhalter DJ. A re-evaluation of random-effects meta-analysis. J R Stat Soc Ser A Stat Soc. 2009;172:137-59.

12. Gwon HC, Hahn JY, Park KW, et al. Six-month versus 12-month dual antiplatelet therapy after implantation of drug-eluting stents: the efficacy of xience/promus versus cypher to reduce late loss after Stenting (EXCELLENT) randomized, multicenter study. Circulation. 2012;125:505-13.

13. Kim BK, Hong MK, Shin DH, et al. A new strategy for discontinuation of dual antiplatelet therapy: the RESET trial (REal safety and efficacy of 3-month dual antiplatelet therapy following endeavor zotarolimus-eluting stent implantation). J Am Coll Cardiol. 2012;60:1340-8.

14. Valgimigli M, Campo G, Monti M, et al. Short-versus long-term duration of dual-antiplatelet therapy after coronary stenting: a randomized multicenter trial. Circulation. 2012;125:2015-26.

15. Feres F, Costa RA, Abizaid A, et al. Three vs. twelve months of dual antiplatelet therapy after zotarolimus-eluting stents: the OPTIMIZE randomized trial. JAMA. 2013;310:2510-22.

16. Colombo A, Chieffo A, Frasheri A, et al. Second-generation drugeluting stent implantation followed by 6- versus 12 -month dual antiplatelet therapy: the SECURITY randomized clinical trial. J Am Coll Cardiol. 2014;64:2086-97.

17. Schulz-Schupke S, Byrne RA, Ten Berg JM, et al. ISAR-SAFE: a randomized, double-blind, placebo-controlled trial of 6 vs. 12 months of clopidogrel therapy after drug-eluting stenting. Eur Heart J. 2015;36:1252-63.

18. Gilard M, Barragan P, Noryani AA, et al. 6- versus 24-month dual antiplatelet therapy after implantation of drug-eluting stents in patients nonresistant to aspirin: the randomized, multicenter ITALIC trial. J Am Coll Cardiol. 2015;65:777-86.

19. Han Y, Xu B, Xu K, et al. Six versus 12 months of dual antiplatelet therapy after implantation of biodegradable polymer sirolimus-eluting stent: randomized substudy of the I-LOVE-IT 2 trial. Circ Cardiovasc Interv. 2016;9:e3145.

20. Hong SJ, Shin DH, Kim JS, et al. 6-month versus 12-month dualAntiplatelet therapy following long everolimus-eluting stent implantation: the IVUS-XPL randomized clinical trial. Jacc Cardiovasc Interv. 2016;9:1438-46.
21. Cassese S, Byrne RA, Tada T, King LA, Kastrati A. Clinical impact of extended dual antiplatelet therapy after percutaneous coronary interventions in the drug-eluting stent era: a meta-analysis of randomized trials. Eur Heart J. 2012;33:3078-87.

22. Giustino G, Baber U, Sartori S, et al. Duration of dual antiplatelet therapy after drug-eluting stent implantation: a systematic review and meta-analysis of randomized controlled trials. J Am Coll Cardiol. 2015;65:1298-310.

23. Bulluck H, Kwok CS, Ryding AD, Loke YK. Safety of short-term dual antiplatelet therapy after drug-eluting stents: an updated metaanalysis with direct and adjusted indirect comparison of randomized control trials. Int J Cardiol. 2015;181:331-9.

24. Valgimigli M, Park SJ, Kim HS, et al. Benefits and risks of long-term duration of dual antiplatelet therapy after drug-eluting stenting: a meta-analysis of randomized trials. Int $\mathrm{J}$ Cardiol. 2013;168:2579-87.

25. Navarese EP, Andreotti F, Schulze V, et al. Optimal duration of dual antiplatelet therapy after percutaneous coronary intervention with drug eluting stents: meta-analysis of randomised controlled trials. BMJ. 2015;350:h1618.

26. Elmariah S, Mauri L, Doros G, et al. Extended duration dual antiplatelet therapy and mortality: a systematic review and meta-analysis. Lancet. 2015;385:792-8.

27. Cassese S, Byrne RA, Ndrepepa G, Schunkert H, Fusaro M, Kastrati A. Prolonged dual antiplatelet therapy after drug-eluting stenting: meta-analysis of randomized trials. Clin Res Cardiol. 2015;104:887-901.

28. Udell JA, Bonaca MP, Collet JP, et al. Long-term dual antiplatelet therapy for secondary prevention of cardiovascular events in the subgroup of patients with previous myocardial infarction: a collaborative meta-analysis of randomized trials. Eur Heart J. 2016;37:390-9.

29. Yusuf S, Zhao F, Mehta SR, et al. Effects of clopidogrel in addition to aspirin in patients with acute coronary syndromes without STsegment elevation. N Engl J Med. 2001;345:494-502.

30. Palmerini T, Riva DD, Benedetto U, et al. Three, six, or twelve months of dual antiplatelet therapy after DES implantation in patients with or without acute coronary syndromes: an individual patient data pairwise and network meta-analysis of six randomized trials and 11473 patients. Eur Heart J. 2017;38:1034-43.

31. Genereux P, Giustino G, Witzenbichler B, et al. Incidence, predictors, and impact of post-discharge bleeding after percutaneous coronary intervention. J Am Coll Cardiol. 2015;66:1036-45.

32. Brener SJ, Kirtane AJ, Stuckey TD, et al. The impact of timing of Ischemic and hemorrhagic events on mortality after percutaneous coronary intervention: the ADAPT-DES study. Jacc Cardiovasc Interv. 2016;9:1450-7. 


CVOI E-learning formula!
This is the CVOI e-learning article. The author has prepared 10 questions which are
available through the website of the Cardiovascular Educational Institute (CVOI).
Please follow the instructions below.
After finishing the questions you will be asked to fill in your name, hospital and e-mail address; then press the button
verzenden'.
When 6 out of the 10 questions are answered correctly, you acquire 1 accreditation point granted by the Quality Committee
of the Netherlands Society of Cardiology (NVVC). The acquired point will be credited to your personal file in the GAIA
system. You will also receive an e-mail with all the correct answers.
Over a period of one year 10 e-learning articles will appear in 10 subsequent NHJ editions. In each edition the e-learning
article will be recognisable by a special icon. On an annual basis you can collect 10 accreditation points. The accreditation
points are credited in the GAIA system by the CVOI.
If you need additional information, please contact the CVOI by e-mail: cvoi@ croi.org or by phone: 030-2345001.
J.J. Piek
Chief editor NHJ
Coordinator CVOI

